\title{
Penerapan Model Pembelajaran REACT dalam Peningkatan Pemahaman Konsep Siswa
}

\author{
${ }^{1}$ Aswar Anas, ${ }^{2}$ Fitriani A \\ ${ }^{12}$ Universitas Cokroaminoto Palopo \\ Jl. Latamacelling B 19 Palopo, Sulawesi Selatan, Indonesia \\ Email:12aswaranasspd8@gmail.com,2fitrianhy77@yahoo.com
}

\section{Article History:}

Received: 22-09-2018; Received in revised form: 14-11-2018; Accepted: 21-11-2018;

Available online: $30-12-2018$

\begin{abstract}
Application of the REACT Learning Models in Increasing the Understanding of Students' Concepts. This research is a quasi-experimental research with a class that aims to know: (1) How is the description of students' understanding of mathematical concepts before and after the application of the REACT learning model. And (2) Is there an increase in students' understanding of concepts after the application of the REACT model. In this study using a concept understanding test instrument. From the results of the study, it was concluded that. (1) The application of the REACT learning model can change the average understanding of students' mathematical concepts from low categories to high categories. (2) Increasing understanding of mathematical concepts students on average are in the medium category. And (3) There is an increase in understanding of students' mathematical concepts with the application of REACT learning models.
\end{abstract}

Keywords: REACT Learning Models; Understanding Student Mathematical Concepts.

Abstrak

Penerapan Model Pembelajaran REACT dalam Peningkatan Pemahaman Konsep Siswa. Penelitian ini merupakan penelitian eksperimen semu dengan satu kelas yang bertujuan untuk mengtahui: (1) Bagaimana gambaran pemahaman konsep matematika siswa sebelum dan setelah penerapan model pembelajaran REACT. Dan (2) Apakah terdapat peningkatan pemahaman konsep siswa setelah penerapan model REACT. Pada penelitian ini menggunakan istrumen tes pemahaman konsep. Dari hasil penelitian diperoleh kesimpulan bahwa. (1) Penerapan model pembelajaran REACT dapat mengubah rata-rata pemahaman konsep matematika siswa dari kategori rendah menjadi kategori tinggi. (2) Peningkatan pemahaman konsep matematika siswa rata-rata berada pada kategori sedang. Dan (3) Terdapat peningkatan pemahaman konsep matematika siswa dengan penerapan model pembelajaran REACT.

Kata Kunci: Model REACT; Pemahamn Konsep Matematika Siswa. 


\section{Pendahuluan}

Pendidikan memiliki peranan yang sangat penting dalam kehidupan berbangsa dan bernegara. Ketika generasi-generasi muda memiliki pendidikan yang baik maka tentu perkembangan bangsa kita akan jauh lebih baik. Tentunya pendidikan akan baik dengan adanya pembelajaran yang baik yang diberikan pendidik kepada peserta didik baik itu dalam pendidikan secara formal maupun informal.

Pembelajaran yang baik khususnya pada pendidikan secara formal sangat mempengaruhi kualitas luaran peserta didik. Peserta didik yang mendapatkan pembelajaran yang baik di sekolah akan turut meningkatkan ilmu pengetahuan peserta didik dan begitupun sebaliknya. Salah satu yang menjadi perhatian peneliti dalam penelitian ini adalah pembelajaran matematika.

Matematika mempunyai visi pada dua arah pengembangan, yaitu untuk memenuhi kebutuhan masa kini dan kebutuhan masa datang. Visi pertama mengarahkan pembelajaran matematika untuk pemahaman konsep dan ide matematika yang kemudian diperlukan untuk menyelesaikan masalah matematika dan ilmu pengetahuan lainnya. Visi kedua dalam artian yang lebih luas dan mengarah ke masa depan, matematika memberi peluang berkembangnya kemampuan menalar yang logis, sistematik, kritis dan cermat, kreatif, menumbuhkan rasa percaya diri1.

Visi pertama yang menyatakan bahwa pemahaman konsep merupakan salah satu bagian terpenting dalam pembelajaran matematika didukung oleh Zulkardi yang menyatakan bahwa mata pelajaran matematika menekankan pada konsep. Tujuan pembelajaran matematika dalam Permendiknas nomor 22 tahun 2006 ialah siswa diharapkan mampu memahami konsep matematika yang diberikan dan menjelaskan keterkaitan antar konsep yang ada serta mampu mengaplikasikannya ke dalam pemecahan masalah secara tepat dan efisien sehingga terjadilah pembelajaran yang bermakna ${ }^{2}$.

Ruseffendi mengemukakan bahwa terdapat banyak siswa yang setelah belajar matematika, tidak mampu memahami bahkan pada bagian yang paling sederhana sekalipun, banyak konsep yang dipahami secara keliru sehingga matematika dianggap sebagai ilmu yang sukar, ruwet, dan sulit. Sulit, kata

${ }^{1}$ Rosliana Harahap, Izwita Dewi, dan Sumarno, "Perbedaan Peningkatan Kemampuan Komunikasi Dan Koneksi Matematis Siswa Melalui Pembelajaran Kontekstual Dengan Kooperatif Tipe Stad Di SMP Al-Washliyah 8 Medan," PARADIKMA JURNAL PENDIDIKAN MATEMATIKA 5, no. 2 (30 Desember 2012), https://doi.org/10.24114/paradikma.v5i2.1092.

2 Yuni Purwanti, "Perbandingan Pemahaman Konsep Matematis Siswa Antara Pembelajaran Problem Based Learning Dengan Pembelajaran PQ4R" (Universitas Lampung, 2016), 3 . 
itulah yang sering kita dengarkan ketika kita bertanya kepada peserta didik tentang apa yang ada dibenaknnya ketika mendengar kata matematika ${ }^{3}$.

Pernyataan tersebut sesuai dengan hasil wawancara kepada guru matematika kelas VIII di SMP Negeri 7 Palopo, diperoleh informasi bahwa dalam mengerjakan soal cerita atau soal-soal yang berkaitan dengan kehidupan sehari-hari sering mengalami kesulitan. Hal ini dikarenakan pada saat proses pembelajaran rata-rata siswa hanya menghafal rumus yang diberikan tanpa memahami konsep-konsepnya.

Peningkatan pemahaman konsep matematika siswa perlu diupayakan demi tercapainya keberhasilan siswa dalam belajar, terutama dalam penyelesaian soal matematika yang diberikan dan dapat mengaplikasikannya ke dalam dunia nyata. Konsep-konsep dalam matematika terorganisasi secara sistematis, logis, dan hirarkis dari yang paling sederhana ke yang paling kompleks. Pemahaman konsep matematika merupakan dasar untuk belajar matematika secara bermakna. Namun, pentingnya pemahaman konsep tersebut tidak sejalan dengan kemampuan pemahaman konsep yang telah dicapai siswa pada saat ini. Hal ini ditunjukan melalui data hasil penelitian terdahulu yang dilakukan oleh Purwanti yang menyatakan bahwa siswa sering mengalami kesulitan ketika mengerjakan soal cerita atau soal yang berkaitan dengan kehidupan sehari-hari. Hal ini dikarenakan siswa hanya hafal rumus tanpa memahami konsep-konsepnya ${ }^{4}$

Pemahaman konsep matematika memberikan pengertian bahwa materimateri yang diajarkan kepada siswa bukan hanya sebagai hafalan, tetapi dengan pemahaman siswa lebih mengerti akan konsep materi pelajaran itu sendiri. Pemahaman tersebut ditandai dengan kemampuan dalam menjelaskan dengan kata-kata sendiri, membandingkan, membedakan, dan mempertentangkan ide yang diperoleh dengan ide yang baru ${ }^{5}$

Hal ini sesuai dengan indikator yang menunjukan pemahaman konsep menurut Depdiknas antara lain:

a. Menyatakan ulang sebuah konsep

b. Mengklasifikasikan objek menurut sifat-sifat tertentu (sesuai dengan konsepnya)

c. Memberi contoh dan bukan contoh dari konsep.

d. Menyajikan konsep dalam berbagai bentuk representasi matematis.

e. Mengembangkan syarat perlu dan syarat cukup suatu konsep.

\footnotetext{
${ }^{3}$ Purwanti, 2.

${ }^{4}$ Purwanti, 2.

${ }^{5}$ Trysa Gustya Manda, "Pemahaman Konsep Luas Dan Volume Bangun Ruang Sisi Datar Siswa Melalui Penggunaan Model Learning Cycle 5e Disertai Peta Konsep," Jurnal Pendidikan $\begin{array}{lllllll}\text { Matematika } & 1, & \text { no. } & 1 & \text { 30 272): }\end{array}$ http://ejournal.unp.ac.id/students/index.php/pmat/article/view/1153.
} 
f. Menggunakan, memanfaatkan dan memilih prosedur atau operasi tertentu.

g. Mengaplikasikan konsep atau algoritma pemecahan masalah ${ }^{6}$

Model pembelajaran REACT merupakan salah satu model pembelajaran yang dapat digunakan guru dalam menanamkan pemahaman konsep matematika siswa. Selamet (dalam Rahayu, 2017:1) menyatakan dalam pembelajarannya REACT menerapkan pembelajaran yang bersifat generatif (kontruktivisme) yaitu mengaitkan pengalaman dengan pengetahuan dan menanamkan kebermaknaan belajar yang dibangun dalam diri siswa sehingga memudahkan dalam mempelajari matematika terutama dalam membentuk konsep ${ }^{7}$. Menurut Cord REACT merupakan pembelajaran kontekstual yang terdiri dari lima strategi yang harus tampak yaitu: (1) Relating (mengaitkan), (2) Experiencing (mengalami), (3) Applying (menerapkan), (4) Cooperating (bekerjasama), (5) Transferring (mentransfer) ${ }^{8}$. Relating (mengaitkan) adalah belajar dalam konteks pengalaman kehidupan nyata atau pengetahuan yang sebelumnya. Experiencing (mengalami) merupakan strategi belajar dengan belajar melalui explorasi, penemuan dan penciptaan. Berbagai pengalaman dalam kelas dapat mencakup penggunaan manipulatif, aktivitas pemecahan masalah dan laboratorium. Applying (menerapkan) adalah belajar dengan menempatkan konsep-konsep untuk digunakan, dengan memberikan latihan-latihan yang realistik dan relevan. Cooperating (bekerjasama) adalah belajar dalam konteks sharing, merespon dan berkomunikasi dengan para pemelajar lainnya. Kemudian Transferring (mentransfer) adalah belajar dengan menggunakan pengetahuan dalam konteks baru.

Kelebihan dari model ini yaitu memiliki strategi pemahaman yang bertahap, dari pemahaman dasar yang diharapkan muncul pada tahap 'Applying'dan pemahaman mendalam pada tahap 'Transferring'. Pemahaman yang bertahap dapat membantu mengefektifkan kemampuan berpikir siswa ${ }^{9}$.

REACT mampu meningkatkan pemahaman dan pemecahan masalah matematika siswa SMP10 dan SMA ${ }^{11}$. Lebih lanjut, REACT memiliki pengaruh

${ }^{6}$ Manda, 26.

${ }^{7}$ Nia Risti Rahayu, "Pengaruh Model Pembelajaran React Dan Guided Discovery Learning Terhadap Pemahaman Konsep Matematika Siswa" (Skripsi, Universitas Muhammadiyah Ponorogo, 2017).

8 Anna Fauziah, "Peningkatan Kemampuan Pemahaman Dan Pemecahan Masalah Matematik Siswa SMP Melalui Strategi REACT (Relating, Experiencing, Applying, Cooperating, Transferring)" (masters, Universitas Pendidikan Indonesia, 2010), http://repository.upi.edu.

9 Aulia Hikmah Durotulaila, Mohammad Masykuri, dan Bakti Mulyani, "Pengaruh Model Pembelajaran React (Relating, Experiencing, Applying, Cooperating, Transfering) Dengan Metode Eksperimen Dan Penyelesaian Masalah Terhadap Prestasi Belajar Ditinjau Dari Kemampuan Analisis Siswa," Jurnal Pendidikan Kimia 3, no. 4 (15 September 2014): 66-74-74.

${ }^{10}$ Fauziah, "Peningkatan Kemampuan Pemahaman Dan Pemecahan Masalah Matematik Siswa SMP Melalui Strategi REACT (Relating, Experiencing, Applying, Cooperating, Transferring)." 
yang cukup siginifikan terhadap keterampilan proses sains siswa SMP ${ }^{12}$. Dengan demikian, model REACT adalah salah satu model pembelajaran yang dapat meningkatkan pemahaman konsep siswa.

Berdasarkan hal tersebut maka penelitian ini mencoba mendeskripsikan pemahaman konsep matematika siswa sebelum dan setelah penerapan model pembelajaran REACT serta ingin mengetahui peningkatan pemahaman konsep siswa setelah penerapan model pembelajaran REACT.

\section{Metode}

Jenis penelitian ini adalah penelitian eksperimen semu (Quasi Eksperimen) dengan desain Pretest Posttest Design. Penelitian ini dilaksanakan di SMP Negeri 7 Palopo yang terletak di Jalan Andi Pangerang No. 6, Kelurahan Luminda Kecamatan Wara Utara, Kota Palopo. Populasi pada penelitian ini yaitu seluruh siswa kelas VIII. Sampel dalam penelitian ini adalah siswa kelas VIIIA dari jumlah populasi seluruh siswa kelas VIII. Sampel dipilih dengan menggunakan teknik purposive sampling. penelitian ini dilaksanakan pada bulan Maret sampai April semester genap tahun ajaran $2017 / 2018$. Instrumen yang digunakan adalah tes pemahaman konsep siswa yang telah diuji validitas dan reliabilitasnya terlebih dahulu.

Data yang diperoleh kemudian dianalisis secara deksriptif dan inferensial. Analisis inferensial yang dilakukan menggunakan analisis nilai gain pemahaman konsep dngan menggunakan uji one sample T Test.

\section{Pemahaman Konsep Matematika Siswa Sebelum dan Setelah Penerapan Model Pembelajaran REACT}

Hasil analisis statistika deskriptif berkaitan dengan skor hasil test pemahaman konsep matematika siswa sebelum dan setelah penerapan model REACT dapat disajikan dalam tabel berikut:

11 Fadhila El Husna, "Penerapan Strategi React Dalam Meningkatkan Kemampuan Pemahaman Konsep Matematika Siswa Kelas X SMAN 1 Batang Anai," Jurnal Pendidikan

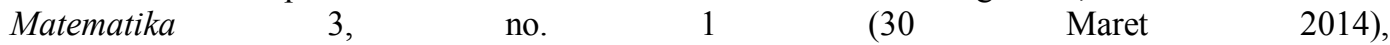
http://ejournal.unp.ac.id/students/index.php/pmat/article/view/1202.

${ }^{12}$ K. Selamet, I. W. Sadia, dan K. Suma, "Pengaruh Model Pembelajaran Kontekstual REACT Terhadap Pemahaman Konsep Fisika Dan Keterampilan Proses Sains Siswa Kelas VIII SMP," Jurnal Pendidikan Dan Pembelajaran IPA Indonesia 3, no. 1 (5 Juli 2013), http://oldpasca.undiksha.ac.id/e-journal/index.php/jurnal_ipa/article/view/751. 
Tabel 1. Distribusi Skor Pemahaman Konsep Siswa sebelum Penerapan Model Pembelajaran REACT

\begin{tabular}{ccccc}
\hline No & Skor & Frekuensi & $\begin{array}{c}\text { Persentasi } \\
(\%)\end{array}$ & Kategori \\
\hline 1 & $0 \leq H B<40$ & 8 & 36,36 & Sangat Rendah \\
2 & $40 \leq H B<60$ & 12 & 54,54 & Rendah \\
3 & $60 \leq H B<75$ & 2 & 9,1 & Sedang \\
4 & $75 \leq H B<90$ & 0 & 0 & Tinggi \\
5 & $90 \leq H B<100$ & 0 & 0 & Sangat Tinggi \\
\hline & Jumlah & 22 & 100 & \\
\hline Mean & Std.Deviasi & Variansi & Minimum & Maksimum \\
\hline 43,32 & 12,56 & 157,751 & 20 & 60 \\
\hline
\end{tabular}

Sumber: Data Primer Hasil Penelitian

Adapun hasil analisis statistika deskriptif setelah penerapan model REACT dapat disajikan dalam Tabel 2 berikut:

Tabel 2. Distribusi Skor Pemahaman Konsep Siswa Setelah Penerapan Model Pembelajaran REACT

\begin{tabular}{ccccc}
\hline No & Skor & Frekuensi & $\begin{array}{c}\text { Persentasi } \\
(\%)\end{array}$ & Kategori \\
\hline 1 & $0 \leq H B<40$ & 0 & 0 & Sangat Rendah \\
2 & $40 \leq H B<60$ & 0 & 0 & Rendah \\
3 & $60 \leq H B<75$ & 11 & 50 & Sedang \\
4 & $75 \leq H B<90$ & 8 & 36,36 & Tinggi \\
5 & $90 \leq H B<100$ & 3 & 13,64 & Sangat Tinggi \\
\hline & Jumlah & 22 & 100 & \\
\hline Mean & Std.Deviasi & Variansi & Minimum & Maksimum \\
\hline 76,59 & 12,21 & 149,015 & 60 & 98 \\
\hline
\end{tabular}

Sumber: Data Primer Hasil Penelitian

Pada Tabel 1 menunjukkan bahwa rata-rata skor pemahaman konsep siswa sebelum penerapan model pembelajaran REACT adalah 43,32 dari skor ideal 100 yang berarti Pemahaman konsep siswa sebelum penerapan model pembelajaran REACT berada dalam kategori rendah. Hal ini berbeda setelah penerapan model pembelajaran REACT yang terlihat pada Tabel 2 yang menunjukkan bahwa rata-rata skor pemahamn konsep siswa setelah penerapan model REACT sebesar 76,59 yang berada pada kategori Tinggi. Dengan data tersebut dapat ditarik sebuah kesimpulan bahwa dengan penerapan model pembelajaran REACT dapat mengubah rata-rata pemahaman konsep matematika siswa dari kategori rendah menjadi kategori tinggi. 
Pada Tabel 1 juga terlihat bahwa tidak ada siswa yang memiliki pemahaman konsep pada kategori tinggi dan sangat tinggi. Hal ini berbeda pada Tabel 2 yang menunjukkan bahwa terdapat siswa yang pemahaman konsepnya berada pada kategori tinggi dan sangat tinggi bahkan dari data pada Tabel 2 juga terlihat bahwa tidak ada siswa yang berada pada kategri sangat rendah dan rendah.

Pada Tabel 1 dan Tabel 2 juga terlihat perbedaan nilai minimum dan maksimum dari skor pemahaman konsep dimana skor maksimum sebelum penerapan model pembelajaran REACT sama dengan skor minimum pemahaman konsep matematika siswa setelah penerapan model pembelajaran REACT.

Berdasarkan skor pemahaman konsep matematika siswa sebelum dan setelah penerapan model pembelajaran REACT, maka diperoleh klasifikasi gain ternormalisasi sebagai berikut:

Tabel. 3. Klasifikasi Gain Ternormalisasi Pada Pemahaman Konsep Matematika Siswa

\begin{tabular}{cccc}
\hline $\begin{array}{c}\text { Koefisien } \\
\text { normalisasi gain }\end{array}$ & Jumlah siswa & Presentase(\%) & Kalsifikasi \\
\hline$g<0,3$ & 1 & 4,54 & Rendah \\
$0,3 \leq g<0,7$ & 16 & 72.73 & Sedang \\
$g \geq 7,0$ & 5 & 22,73 & Tinggi \\
\hline Rata-rata & & $\mathbf{0 . 6 1}$ & Sedang \\
\hline
\end{tabular}

Sumber: Data Primer Hasil Penelitian

Pada Tabel 3 terlihat bahwa rata-rata gain ternormalisasi pemahaman konsep matematika berada pada skor 0,61 dimanan skor tersebut berada pada kategori sedang. Hal ini dapat disimpulkan bahwa peningkatan pemahaman konsep matematika siswa rata-rata berada pada kategori sedang.

\section{Peningkatan Pemahaman Konsep Matematika dengan Penerapan Model Pembelajaran REACT}

Uji prasyarat sebelum pelaksanaan uji hipotesis pada penelitian ini adalah uji normalitas yang diuji dengan menggunakan aplikasi SPSS 20. Hasil analisis dapat ditunjukkan pada Gambar 1 berikut: 
Tests of Normality

\begin{tabular}{|l|r|r|r|r|r|c|}
\hline \multirow{2}{*}{} & \multicolumn{3}{|c|}{ Kolmogorov-Smirnov $^{\mathrm{a}}$} & \multicolumn{3}{c|}{ Shapiro-Wilk } \\
\cline { 2 - 7 } & Statistic & \multicolumn{1}{c|}{$\mathrm{df}$} & \multicolumn{1}{c|}{ Sig. } & Statistic & \multicolumn{1}{c|}{$\mathrm{df}$} & Sig. \\
\hline Gain & .107 & 22 & .200 & .967 & 22 & .636 \\
\hline
\end{tabular}

${ }^{*}$. This is a lower bound of the true significance.

a. Lilliefors Significance Correction

Gambar 1. Uji Normalitas Gain Ternormalisasi

Berdasarkan Gambar 1. terlihat bahwa test of normality dengan Shapiro-Wilk menunjukkan bahwa nila sig. $=0,636$ dimana nilai sig. $>0,05$. Hal ini menunjukkan bahwa data berdistribusi normal sehingga pada penelitian ini kita bias melanjutkan uji hipotesis kita untuk melihat ada tidaknya peningkatan pemahaman konsep siswa setelah penerapan model pembelajaran REACT. Hasil analisis uji hipotesis dapat ditunjukkan pada Gambar 2 berikut:

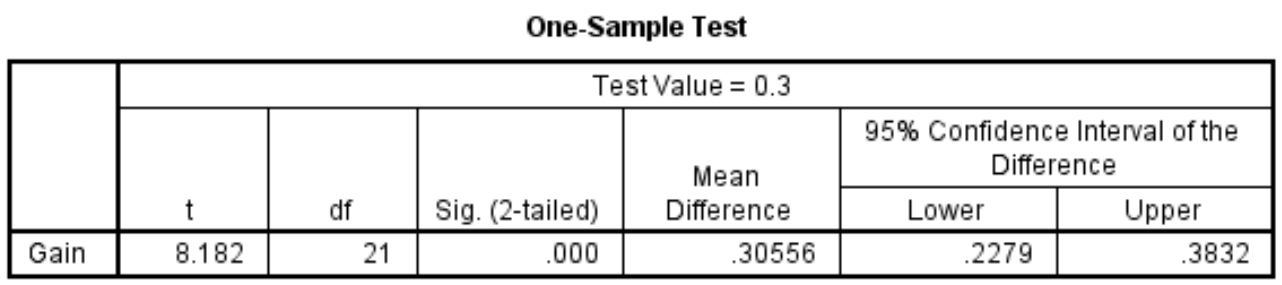

Gambar 2. Uji Hipotesis dengan Uji One Sample T Test

Berdasarkan Gambar 2 terlihat bahwa nilai t hitung adalah 8,182 dengan $\mathrm{df}=21$ dimana dengan menggunakan tabel $\mathrm{t}$ diketahui $\mathrm{t}$ tabel $=2,07961$. Dari data tersebut diketahui bahwa $t$ hitung $(8,182)>t$ tabel $(2,07961)$ sehingga terdapat peningkatan pemahaman konsep matematika siswa dengan penerapan model pembelajaran REACT. Hasil ini sejalan dengan hasil penelitian yang menyatakan bahwa REACT dapat meningkatkan kemampuan pemahaman siswa ${ }^{13}$. Hasil penelitian lain mengatakan bahwa Penerapan strategi Relating, Experiencing, Applying, Cooperating, dan Transferring (REACT) dapat memberikan pengaruh baik dalam meningkatkan kemampuan pemahaman konsep matematika siswa ${ }^{14}$. Hasil penelitian ini juga sejalan dengan penelitian lain ${ }^{15}$. yang mengatakan bahwa model pembelajaran

${ }^{13}$ Fauziah, "Peningkatan Kemampuan Pemahaman Dan Pemecahan Masalah Matematik Siswa SMP Melalui Strategi REACT (Relating, Experiencing, Applying, Cooperating, Transferring)."

14 Husna, "Penerapan Strategi React Dalam Meningkatkan Kemampuan Pemahaman Konsep Matematika Siswa Kelas X SMAN 1 Batang Anai."

15 Selamet, Sadia, dan Suma, "Pengaruh Model Pembelajaran Kontekstual REACT Terhadap Pemahaman Konsep Fisika Dan Keterampilan Proses Sains Siswa Kelas VIII SMP.” 
REACT melalui lima komponennya yang penting dalam pembelajaran terbukti memiliki pengaruh yang lebih unggul terhadap pemahaman konsep siswa dan keterampilan proses sains siswa dibandingkan dengan model pembelajaran konvensional

\section{Penutup}

\section{Simpulan}

Berdasarkan hasil pembahasan pada penelitian ini maka dapat disimpulkan bahwa penerapan model pembelajaran REACT dapat mengubah rata-rata pemahaman konsep matematika siswa dari kategori rendah menjadi kategori tinggi. Peningkatan pemahaman konsep matematika siswa rata-rata juga berada pada kategori sedang. Lebih lanjut, pemahaman konsep matematika siswa setelah penerapan model REACT mengalami peningkatan.

\section{Saran}

Hasil penelitian ini diharapkan dapat menjadi rekomendasi bagi para guru tentang penerapan model pembelajaran REACT.

\section{Ucapan Terimakasih}

Ucapan terimakasih kami sampaikan kepada:

1. Kepala SMPN 7 Palopo yang telah memberikan izin dalam pelaksanan penelitian ini.

2. Ketua LPPM UNCP Palopo yang telah mengeluarkan surat tugas penelitian sehingga penelitian ini bias dilaksanakan.

3. Kepada semua pihak terkait baik secara langsung dan tidak langsung yang turut membantu kelancaran pelnelitian ini.

\section{Daftar Pustaka}

Durotulaila, Aulia Hikmah, Mohammad Masykuri, dan Bakti Mulyani. "Pengaruh Model Pembelajaran React (Relating, Experiencing, Applying, Cooperating, Transfering) Dengan Metode Eksperimen Dan Penyelesaian Masalah Terhadap Prestasi Belajar Ditinjau Dari Kemampuan Analisis Siswa." Jurnal Pendidikan Kimia 3, no. 4 (15 September 2014): 66-74-74.

Fauziah, Anna. "Peningkatan Kemampuan Pemahaman Dan Pemecahan Masalah Matematik Siswa SMP Melalui Strategi REACT (Relating, Experiencing, Applying, Cooperating, Transferring)." Masters, Universitas Pendidikan Indonesia, 2010. http://repository.upi.edu.

Harahap, Rosliana, Izwita Dewi, dan Sumarno. "Perbedaan Peningkatan Kemampuan Komunikasi Dan Koneksi Matematis Siswa Melalui Pembelajaran Kontekstual Dengan Kooperatif Tipe Stad Di SMP AlWashliyah 8 Medan." PARADIKMA JURNAL PENDIDIKAN MATEMATIKA 
5, no. 2 (30 Desember https://doi.org/10.24114/paradikma.v5i2.1092.

Husna, Fadhila El. "Penerapan Strategi React Dalam Meningkatkan Kemampuan Pemahaman Konsep Matematika Siswa Kelas X SMAN 1 Batang Anai." Jurnal Pendidikan Matematika 3, no. 1 (30 Maret 2014). http://ejournal.unp.ac.id/students/index.php/pmat/article/view/1202

Manda, Trysa Gustya. "Pemahaman Konsep Luas Dan Volume Bangun Ruang Sisi Datar Siswa Melalui Penggunaan Model Learning Cycle 5e Disertai Peta Konsep." Jurnal Pendidikan Matematika 1, no. 1 (30 Desember 2012).

http://ejournal.unp.ac.id/students/index.php/pmat/article/view/1153

Purwanti, Yuni. "Perbandingan Pemahaman Konsep Matematis Siswa Antara Pembelajaran Problem Based Learning Dengan Pembelajaran PQ4R." Universitas Lampung, 2016.

Rahayu, Nia Risti. "Pengaruh Model Pembelajaran React Dan Guided Discovery Learning Terhadap Pemahaman Konsep Matematika Siswa." Skripsi, Universitas Muhammadiyah Ponorogo, 2017.

Selamet, K., I. W. Sadia, dan K. Suma. "Pengaruh Model Pembelajaran Kontekstual REACT Terhadap Pemahaman Konsep Fisika Dan Keterampilan Proses Sains Siswa Kelas VIII SMP." Jurnal Pendidikan Dan Pembelajaran IPA Indonesia 3, no. 1 (5 Juli 2013). http://oldpasca.undiksha.ac.id/ejournal/index.php/jurnal_ipa/article/view/751. 